\title{
Quantifying the Reduction in Water Demand due to Rainwater Tank Installations at Residential Properties in Sydney
}

\section{Danious P. Sountharajah ${ }^{1}$, Benjamin Kus ${ }^{2}$, Jaya Kandasamy*3, Saravanamuthu Vigneswaran ${ }^{4}$}

${ }^{1}$ Faculty of Engineering and IT, University of Technology Sydney (UTS), P.O. Box 123, Broadway, NSW 2007, Sydney, Australia

e-mail: daniouspratheep@yahoo.com

${ }^{2}$ Faculty of Engineering and IT, University of Technology Sydney (UTS), P.O. Box 123, Broadway, NSW 2007, Sydney, Australia

e-mail: ben@kustomengineering.com.au

${ }^{3}$ Faculty of Engineering and IT, University of Technology Sydney (UTS), P.O. Box 123, Broadway, NSW 2007, Sydney, Australia e-mail: jaya.kandasamy@uts.edu.au

${ }^{4}$ Faculty of Engineering and IT, University of Technology Sydney (UTS), P.O. Box 123, Broadway, NSW 2007, Sydney, Australia e-mail: s.vigneswaran@uts.edu.au

Cite as: Sountharajah, D. P., Kus, B., Kandasamy, J., Vigneswaran, S., Quantifying the Reduction in Water Demand due to Rainwater Tank Installations at Residential Properties in Sydney, J. sustain. dev. energy water environ. syst., 5(2), pp 202-218, 2017, DOI: http://dx.doi.org/10.13044/j.sdewes.d5.0144

\begin{abstract}
This paper examines data on actual reductions in consumption of water supply due to the widespread installation of rainwater tanks at residential properties in the Sydney metropolitan area and surrounding areas connected to Sydney Water Corporation water supply mains. The water consumption was based on metered potable water usage between 2002 and 2009. The number of properties in the study database totalled 962,697 single residential dwellings. Of this a total of 52,576 or 5.5\% of Sydney's households had a rainwater tank registered with Sydney Water Corporation. The water usage consumption before and after the installation of the rainwater tank was analysed to quantify the extent to which rainwater tanks reduced mains water consumption. The average percentage of water savings by installing rainwater tanks across all 44 local government authorities was $9 \%$. In some Sydney localities this reduction was up to $15 \%$. On average, a household was able to save around 24 kilolitre of water annually by installing a rainwater tank even without considering other factors that affect water usage. The results were compared against socio-demographic factors using variables such as household size, educational qualifications, taxable income, rented properties, and non-English-speaking background, etc., to gain an appreciation of how these factors may have influenced the outcomes evident in the data. Among the co-relations found were that most properties within inner Sydney with a rainwater tank achieved at least a 9 to $11 \%$ additional reduction in water usage, with more than half of those local government authorities achieving more than $11 \%$; properties with larger land area were more likely to have a rainwater tank installed; local government authorities with more people born in non-English speaking countries had lower reduction in water consumption reductions.
\end{abstract}

\footnotetext{
* Corresponding author
} 


\section{KEYWORDS}

Rainwater harvesting, Water demand, Demand management, Sydney, Residential water supply.

\section{INTRODUCTION}

In Australia potable water demand is expected to increase beyond the capacity of current available water supplies due to population increases in capital cities and the reoccurrence of the recent drought exacerbated by climate change. This has forced governments to look at ways of securing alternative water supplies. A number of solutions can be utilised to save water either by reducing demand, increasing efficiency or by increasing the available supply. The former include community education, water restrictions, retrofitting water fixtures to reduce consumption and rebate schemes to promote the installation of rainwater tanks. Methods for increasing available supply include alternative water supplies such as: firstly, desalination and recycling; and secondly, creating alternative but poorer quality supplies from sources such as grey water for local non-potable uses [1].

Kuczera [2] analysed centralised storage and decentralised storage systems to evaluate the extent to which rainwater tanks could complement the mains water supply. Kuczera analysed conditions where rainwater tanks made the most significant contribution to urban water supply drought security. It was found that rainwater tanks can contribute to the drought security of the whole system. The size of typical rainwater tanks means they typically draw down in less than a week, and as a result, depending on the prevailing rainfall pattern, may be empty for considerable periods. However, utilising rainwater tanks can improve city-wide drought security for a given centralised reservoir capacity and for a given threshold probability, as rainwater tanks reduce the required centralised reservoir capacity. Rainwater tanks benefit drought security more when the centralised system is considerably stressed due to the high supply variability or high load and when the per-capita household demand is lower. As the uptake of installing rainwater tanks increased, system drought security increased. However, the growth rate of benefits declines with increasing uptake. The benefits of rainwater tanks were not particularly sensitive to reduced rainfall. This robustness may be an important consideration when periods of reduced rainfall are encountered.

Coombes et al. [3] showed, using continuous modelling and historical sequences, how the available storage or empty portion of rainwater tanks prior to rain events was primarily due to the seasonality of rainfall patterns at each location. Locations such as Brisbane have larger available volumes of storage due to a summer rainfall pattern that is consistent with the expected higher water demands during the same period. In contrast, the lower available storage volumes in Adelaide were due to higher water demands occurring in summer, which was inconsistent with the winter rainfall pattern at that location. The larger available storage volumes in tanks located in Sydney resulted from the higher indoor water demands that balanced the more even pattern of seasonal distribution of rainfall. The available rainwater tank storage volumes prior to rain events increased regardless of location. This was due to the increase of tank capacity, household size and rainfall intensity. Furthermore the storage volume available in a rainwater tank, on average, decreased with larger areas of connected roof.

Several studies have attempted to quantify the savings in potable water that could be achieved by the use of a rainwater tank in households using different methods such as: rainwater system tank modelling [4], paired statistical analysis using water billing data between household cohorts with and without the use of household rainwater tanks [5]; and benchmarking the water usage in households rainwater tanks against regional water usage [6]. 
Coombes and Kuczera [4] found that depending on roof size and number of occupants in a household, the use of rainwater tanks could result in annual mains water savings ranging from $18 \mathrm{~kL}$ to $55 \mathrm{~kL}$ for $1 \mathrm{~kL}$ rainwater tanks to $25 \mathrm{~kL}$ to $144 \mathrm{~kL}$ for $10 \mathrm{~kL}$ rainwater tanks. This was estimated for capital cities in Australia by the Probabilistic Urban Rainwater and wastewater Reuse Simulator (PURRS) model using synthetic pluviograph rainfall generated by the Disaggregated Rectangular Intensity Pulse (DRIP).

A study was conducted in Sydney by Sydney Water Corporation (SWC) by remote monitoring of rainwater usage from 1 July 2009 to 30 June 2010 in 52 newly built houses in compliance with New South Wales's Building Sustainability Index (BASIX) water regulation. It showed an average water savings of $21 \%$ of the total household water demand was due to rainwater tanks, which is equivalent to $38 \mathrm{~kL}$ per household per year of water saving [7]. The houses considered in this study are newly built houses (less than two years old) with large tanks of on average capacity of $4.2 \mathrm{~kL}$; large roof areas, averaging $210 \mathrm{~m}^{2}$, available to collect rain; and high number of direct connections to outdoor taps, washing machines and toilets that use rainwater, and with a demand of $59 \mathrm{~kL}$ per household per year [7]. However this type of rainwater connection and usage is not typical of Sydney households. Most households in the city are old. In new houses rainwater tank are more easily plumbed to directly connect to toilets and washing machines and can be connected to drain larger roof areas. The study was carried out for a relatively short time concentrating on a fraction of Sydney's population.

Beal et al. [6] undertook a desktop study comparing the household water billing data between homes with internally pumped rainwater tanks (or rainwater tanks directly plumbed to toilets and washing machines) and without rainwater tank for a period of 1 year (in 2008) for 3 suburbs in Brisbane, Queensland. The range of estimated reductions for 1,182 houses with rainwater tanks was 20-95 kL per household per year (kL/hh/year), with an average of $50 \mathrm{~kL} / \mathrm{hh} /$ year. The study was based on a much smaller sample and for shorter period than our study. The results were not adjusted for savings resulting from water restrictions. It must be noted that internally pumped rainwater tanks has more potential for greater water saving and only represent around 2,500 out of an estimated 240,000 houses that have rainwater tanks in Queensland [6]. Further it would be worthwhile noting how these savings obtained in Brisbane compared other location (e.g. Sydney) with different climatic conditions.

Moy [8] undertook a post-installation analysis of a group of rainwater tanks installed between 2005 and 2007 in the Wollongong and Shellharbour Local Government Authorities (LGA), towns south of Sydney and their effects on mains water consumption. The study aimed to determine the average mains water reductions achieved in households with rainwater tanks. The results reveal that households with rainwater tanks in Wollongong and Shellharbour reduced their consumption during 2005-2007 by approximately $10.3 \%$. However, the data from these towns were not analysed separately, and given that this was a relatively short period, the analysis did not adjust the data for the change in water consumption occurring in the wider community. The total residential water consumption for Wollongong and Shellharbour LGAs during 2005-2007 indicated that water consumption fell by $3.3 \%$ and $0 \%$, respectively.

Knights et al. [9] presented data from a rainwater tank incentive scheme in Marrickville LGA where pre- and post-rainwater tank installation water usage was examined. The study included real-time metering of mains water and rainwater use of several individual households participating in the program. The results showed that rainwater tanks can reduce water consumption for a household on average by $110 \mathrm{~L} /$ day in a range between $7 \mathrm{~L} /$ day to $390 \mathrm{~L} /$ day. This equates to a reduction in water consumption of $25 \%$. The data was not adjusted for the overall change in water consumption that occurred in the wider community. It was not possible to assess this since the time period over which the analysis took place was not given. 
Households in Sydney account for about $70 \%$ of the total drinking water consumption. The uses of water in and around the home are: $23 \%$ for lawn and garden watering; $4 \%$ for pools, hosing down and car washing; $25 \%$ for showers; $17 \%$ for washing machines; $16 \%$ for kitchen, laundry and bathroom taps; $14 \%$ for toilets; and $1 \%$ for dishwashers [10]. Rainwater tanks may replace potable water used for lawn and garden watering, hosing down and car washing, and laundry and toilet flushing. Indeed SWC provided a higher rebate if the rainwater tank was plumbed for the toilet and laundry. Note lawn and garden watering, hosing down and car washing do not require separate plumbing but can source water directly from the rainwater tank. These imply that, if available, nearly $60 \%$ of household water uses could be provided by rainwater tanks and there is a large potential to reduce water use in Sydney. By 2010, 11.1\% of the Sydney households had rainwater tanks [11].

There are many available studies where the analysis were done on a lot or building scale [12-14]. Those covering water consumption have little data on actual measurements on reduction in water demand from town water supply and mostly determined this using modelling, based on lot/building scale. In effect this is a 'bottom up' approach where analysis or modelling were done on a lot/building scale and the results obtained from were implied on large scale geographical scale. Such analysis is limited by the many socio-economic factors that prevent their proper translation to large scale.

The paper aimed at analysing the water consumption pattern in the Sydney metropolitan area and surrounding areas (Illawarra and Blue Mountains) connected to SWC potable water supply mains. This was based on the metered potable water usage of all single dwelling residential properties between 2002 and 2009. Additionally this paper compares the potable water consumption in residential properties within the greater Sydney metropolitan area against the residential properties that installed a rainwater tank and received a rebate from SWC. The water usage consumption before and after rainwater tank's installation was analysed to quantify the amount by which rainwater tanks reduce water consumption. The results were then compared against socio-demographic factors to provide a commentary of the data and gain insight on how these factors may have influenced the observed water usage.

\section{BACKGROUND AND DATA}

The data used in this study is summarized below.

\section{Climate}

The average rainfall in Sydney from 1913 to 1998 was 1,203 mm/year [15]. The year is sub-divided into quarters that approximately follow the seasons: Q1 from November to January; Q2 from February to April; Q3 from May to July; and Q4 from August to October. The wettest period of the year is generally in the second quarter (Q2) while the driest is the fourth quarter $(\mathrm{Q} 4)$. The average quarterly and yearly rainfall patterns over the study period (2002 to 2009) vary greatly from year to year. The driest year was 2005 with a total annual rainfall of only $808 \mathrm{~mm}$ and the wettest year was 2007 with $1,325 \mathrm{~mm}$ of rainfall. In fact 2005 was the third hottest summer recorded in NSW [16]. Some notable phases during the study period include the fourth quarter of 2002 (Q4-2002) and first quarter of 2003 (Q1-2003) where a total of only $47 \mathrm{~mm}$ and $120 \mathrm{~mm}$ of rainfall occurred respectively; and the third quarter of 2007 (Q3-2007) where a total of $588 \mathrm{~mm}$ of rainfall occurred. This was almost three quarters of the total rainfall that occurred in 2005 and well above the quarterly average.

High average temperatures can be a leading factor for increased water consumption due to the need for additional watering of gardens and lawns and higher overall consumption. The quarterly average temperatures were $25.6{ }^{\circ} \mathrm{C}(\mathrm{Q} 1), 25.2{ }^{\circ} \mathrm{C}(\mathrm{Q} 2)$, 
$19.1^{\circ} \mathrm{C}(\mathrm{Q} 3), 21.7^{\circ} \mathrm{C}(\mathrm{Q} 4)$, and the annual average was $22.9^{\circ} \mathrm{C}$. The hottest part of the year is generally in the first and second quarter (November through to April) while the coldest part of the year is the third quarter (May through to July).

\section{Water restrictions}

SWC implemented various water restrictions over the past decade due to the declining water levels in dams that supply the Sydney metropolitan area [17]. Voluntary restriction commenced in Sydney in October 2002. SWC introduced Level 1 restrictions in October 2003 when dam levels dropped below 60\% [17]. Dam levels continued to decline due to the lack of rainfall in the dams' catchment and by June 2004 were below $50 \%$ when SWC implemented Level 2 restrictions [17]. In June 2005 the dam levels had dropped further to below 40\%, resulting in Level 3 restrictions [17]. Level 3 restrictions remained in place for a number of years. In June 2008, SWC eased Level 3 restrictions to permit its residential customers to wash cars, boats and caravans at home as well as to clean the windows and walls of their house with a hose as long as a trigger nozzle was fitted. By June 2009 water levels in the dam had been steady at around $60 \%$ for 12 months. Level 3 restrictions ceased and SWC brought in new "Water Wise Rules" [17] which are still in effect despite dam water levels currently at $100 \%$.

\section{SWC rainwater tank rebate}

In October 2002, SWC introduced a rainwater tank rebate scheme in an effort to promote the installation of rainwater tanks so that water consumption could be better managed. The scheme provided various rebates (monetary refunds) for their installation. USD 150 was provided for the installation of rainwater tanks with a capacity of between 2,000 to 3,999 L, USD 400 for 4,000 to 6,999 L and USD 500 for more than 7,000 L. Additionally, further monetary incentives (USD 150) were provided to connect the rainwater tank to the household toilet system and/or laundry systems. This rose to USD 300 from October 2006. In July 2007, USD 500 was given for a rainwater tank connected to the household toilet system and/or USD 500 to the laundry systems. This scheme ended in June 2011.

\section{SWC database}

SWC supplies water to properties located in Sydney's metropolitan area. A database of water bills, which are issued quarterly and include the amount of water used at a property, was used to undertake a statistical analysis of residential water usage in Sydney. The database covered the period spanning from November 2001 (Q1-02) to October 2009 (Q4-09). The quarters approximately follow the seasons: Q1 from November to January; Q2 from February to April; Q3 from May to July; and Q4 from August to October. The first quarter in the dataset (Q1) covered the period November 2001 to February 2002. The total number of properties in the database totalled 1,207,359 of which 962,697 were categorised as "Residential - Single Dwelling". By 2009, a total of 52,576 households had registered for a rainwater tank rebate with SWC which represented a $5.5 \%$ of all residential single dwellings supplied by SWC. The average quarterly consumption for these properties with and without rainwater tanks for each Local Government Authority (LGA) was provided. Data was released in this restricted form to comply with SWC's privacy restrictions which prohibits releasing any information pertaining to their individual customers.

The SWC database covers a large data set of various property types, land sizes and water usages. A subset was created - Conditional Data Set - Residential properties (CDSR) - to remove data not used in this study. The CDSR was separated into individual LGAs to provide a location-based investigation and further isolated properties to the following conditions: single dwelling residential properties only; properties with a lot 
area greater than $100 \mathrm{~m}^{2}$ and no larger than $2,000 \mathrm{~m}^{2}$ as larger properties are not typically urban residential; and properties with typical water usage between $10 \mathrm{~kL}$ to $500 \mathrm{~kL}$ per quarter (typically $100 \mathrm{~L}$ to 5,000 L per day). Subsequent to creating the CDSR, a second data set was created with these same conditions except it included only those properties with a registered rainwater tank rebate (CDSRT).

\section{Standardisation of data set}

The CDSRT had to be standardised to ensure that the data set was consistent to make it possible to compare water usage before and after a rainwater tank had been installed. To standardise the data, individual LGA CDSR were graphed to observe the water usage trend over the study period (Q1-02 to Q4-09). The trend in the data was due to the impact of factors that led to changes in water usage other than the rainwater tank. These factors include the effects of SWC's restrictions on water usage, seasonal and climate variations, and the changes in consumers' water usage patterns (e.g. as a result of public education campaigns).

The CDSR data was grouped by LGAs. For each LGA a factor was determined for the average water usage for each quarter relative to the average of each LGAs water usage over the study period (Q1-02 to Q4-09). Subsequently, these factors were applied to the respective individual quarterly water bills of the CDSRT to remove the impact of factors other than the installation and use of rainwater tanks. The data set with factors applied is called the Standardised Conditional Data Set with Rainwater Tanks (S-CDSRT). The outcome of applying the factors to the CDSRT allowed a comparison between water usage, before and after the rainwater tanks were installed with any of the other effects discussed above removed. For a particular house, the plot of S-CDSRT water consumption data would show a sudden drop in the quarter when the rainwater tank was installed. The drop in water consumption before and after installation is reduction in water consumption due to the installation and use of rainwater tanks. The reduction in water consumption was calculated for rainwater tanks over a period of at least two years (8 quarters) before and at least two years after the installation. There were 32,276 properties with rainwater tanks or $61.4 \%$ of the total number of properties with rainwater tanks meeting this criterion. The proportion of rainwater tanks meeting this criterion was over $50 \%$ in all but 6 LGAs. Any decline in the average water usage trend after the installation of the rainwater tank would confirm that it led to a reduction in potable water usage.

\section{RESULTS}

The results of this study is reported first for water consumptions over the period of the study and then the reduction resulting for the installation of rainwater tank.

\section{Water consumption for residential single dwellings}

Figure 1 shows the reduction in water consumption in Sydney and in various LGAs over the period leading up to and including the water restrictions. The overall trend in the data in terms of the times when water consumption rises, falls and plateaus is similar. Water consumption sharply fell during the period of voluntary restriction and reflects: firstly, the community education and publicity campaign to save water; and secondly, the falling of dam storage to critical levels over that period that heightened community concern in that period. The initial saving was so large that the reduction in water consumption level during periods of level 1, 2 and 3 restrictions actually levelled off even when they became increasingly severe. Savings in water consumption became harder to achieve once practices and habits in the community that were easier to change were accomplished. The average reduction in water consumption from 2002 to 2009 was about 
$24 \%$. Not all the saving in water consumption can be attributed to the water restrictions program. Concurrently, during this period other measures were implemented to reduce water consumption. This included the installation of water savings devices such as water efficient shower heads and dual flush toilets, and implementing the Building Sustainability Index (BASIX) for new and refurbished buildings which aimed to deliver effective water reductions in Sydney and across New South Wales. BASIX is a planning initiative of the New South Wales State Government that requires all new dwellings to be designed and built to achieve a $40 \%$ reduction in water consumption and $40 \%$ reduction in greenhouse gas emissions compared to the average dwelling. Another objective was to continually replace water appliances with new and more efficient ones.

Figure 1 shows the variation in water demand in Campbelltown and Hornsby which have the lowest and highest rainfall, respectively. The annual rainfall in Hornsby is approximately double that in Campbelltown. Both suburbs are similar in character with predominantly single dwelling houses and large gardens. Income levels in both suburbs are also similar and reasonably close to the Australian average [18]. While the difference in water consumption between the two LGAs is not large $(<5 \%)$, Hornsby had a slightly lower consumption. The plot also shows the LGAs with the largest (Ku-ring-gai) and smallest (Auburn) reduction in water consumption during the water restrictions period. The former is a wealthy leafy suburb with predominantly single dwelling houses with large gardens while Auburn is a suburb located near the geographical centre of Sydney (20 km from the CBD) with mainly smaller lot areas and smaller outdoor/garden areas. While there was a tangible reduction in both suburbs, the reduction in Ku-ring-gai was substantial. Both Ku-ring-gai and Auburn had similar water consumption patterns at the end of the monitoring period and this was about $10 \%$ larger than the Sydney average.

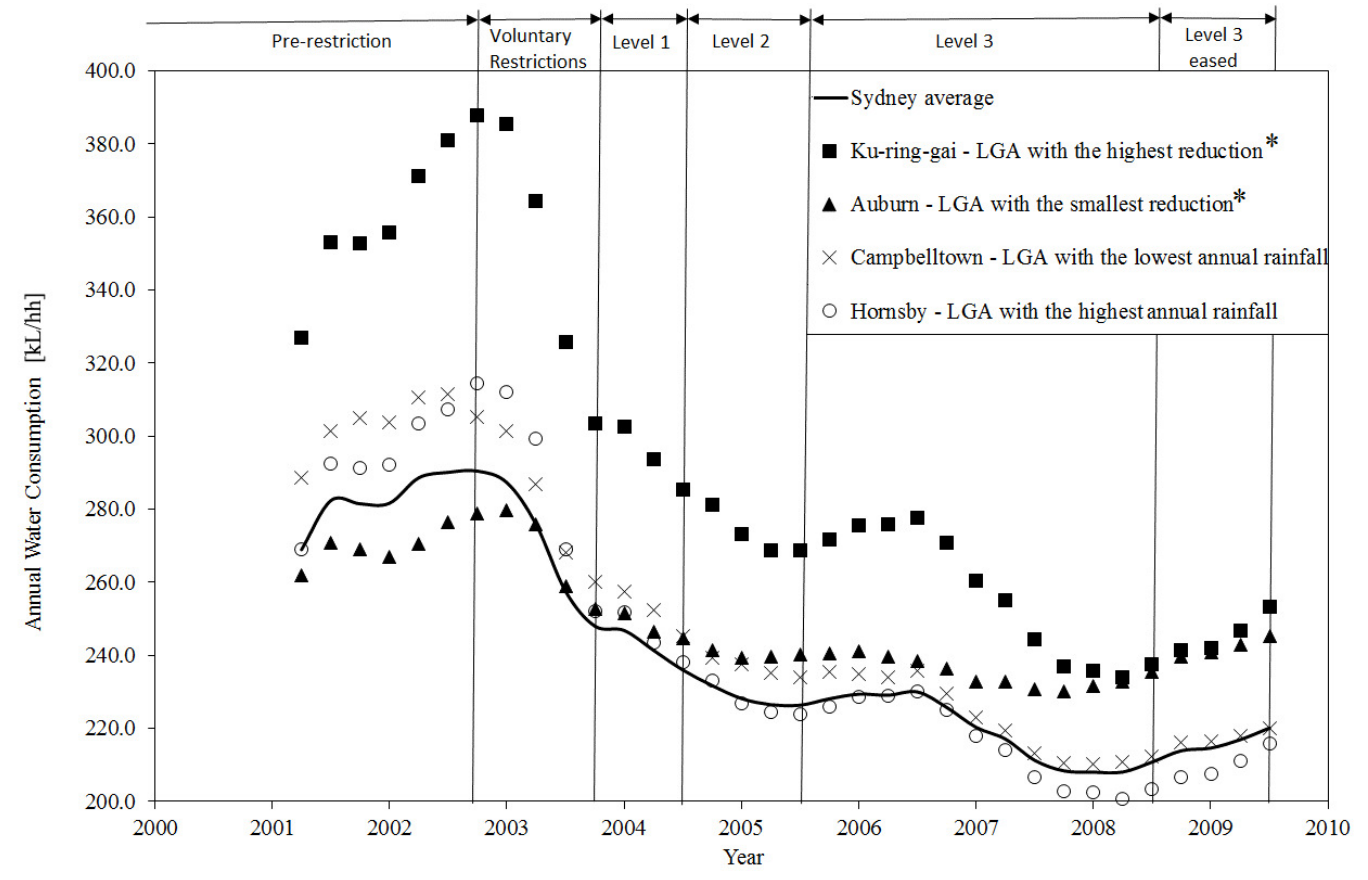

Figure 1. Variation in average water consumption in Sydney and its LGAs

Figures 2-5 present an overview of water consumption in Sydney together with various socio-economic indicators which were prepared from the SWC database together with data from the Australian Bureau of Statistic [19], and the Bureau of Meteorology [15]. The data across Sydney is presented by LGAs. For clarity, the overarching map containing most of the LGAs is referred to as the 'outer Sydney area' and the smaller insert is referred to as the 'inner Sydney area'. 


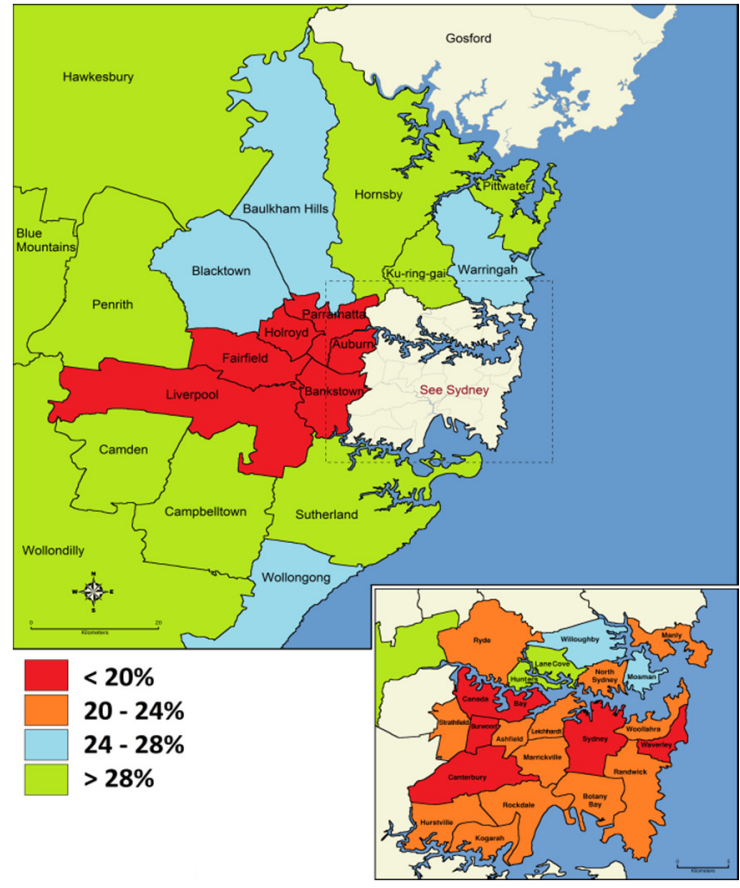

(a) Reduction of water consumption in each LGA over the study period

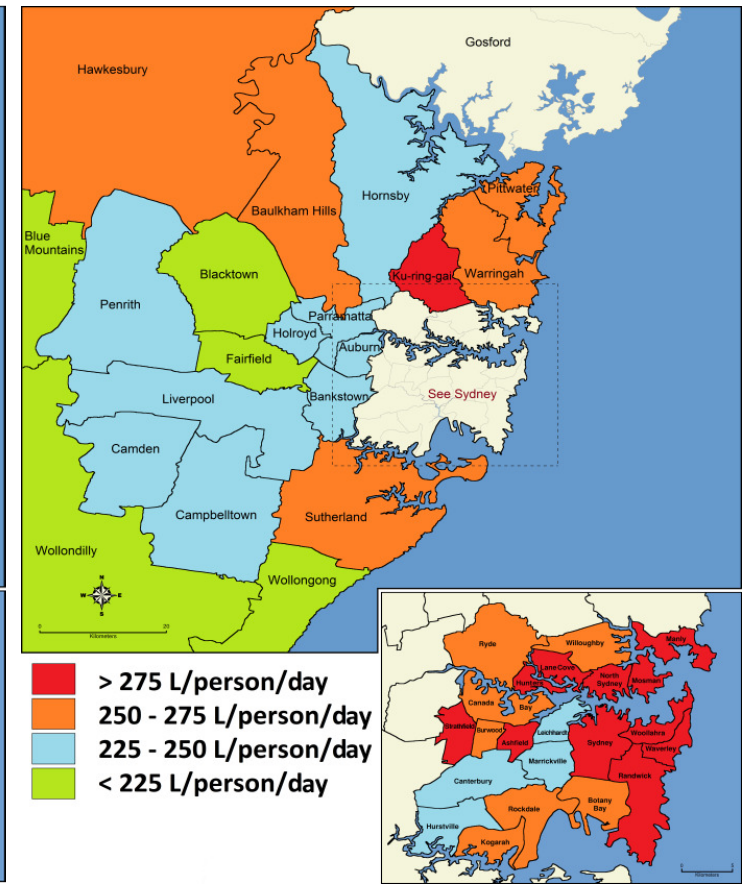

(b) Average daily per capita water usage

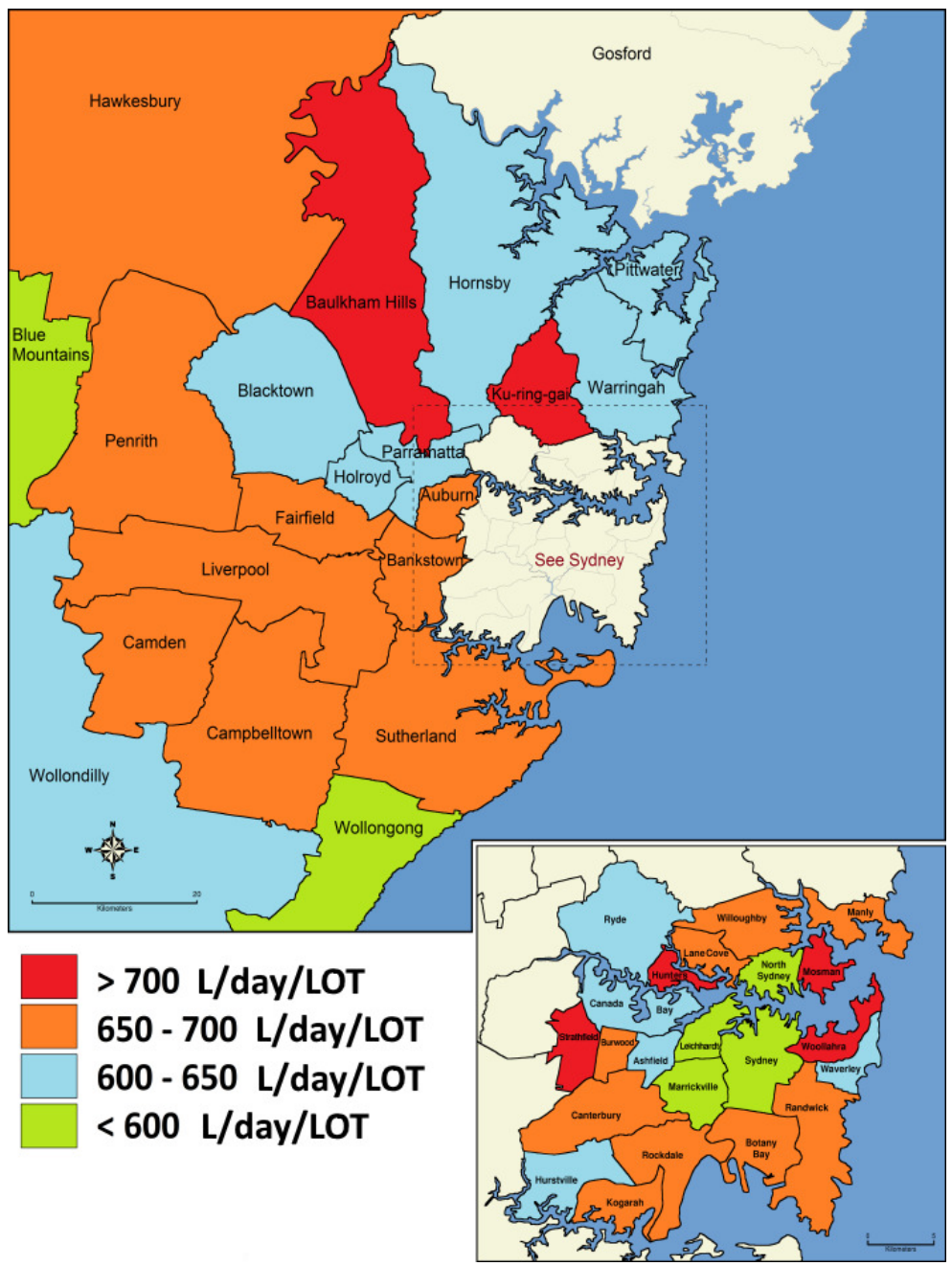

(c) Average daily household water usage

Figure 2. Water consumption for single households in the Sydney metropolitan area 


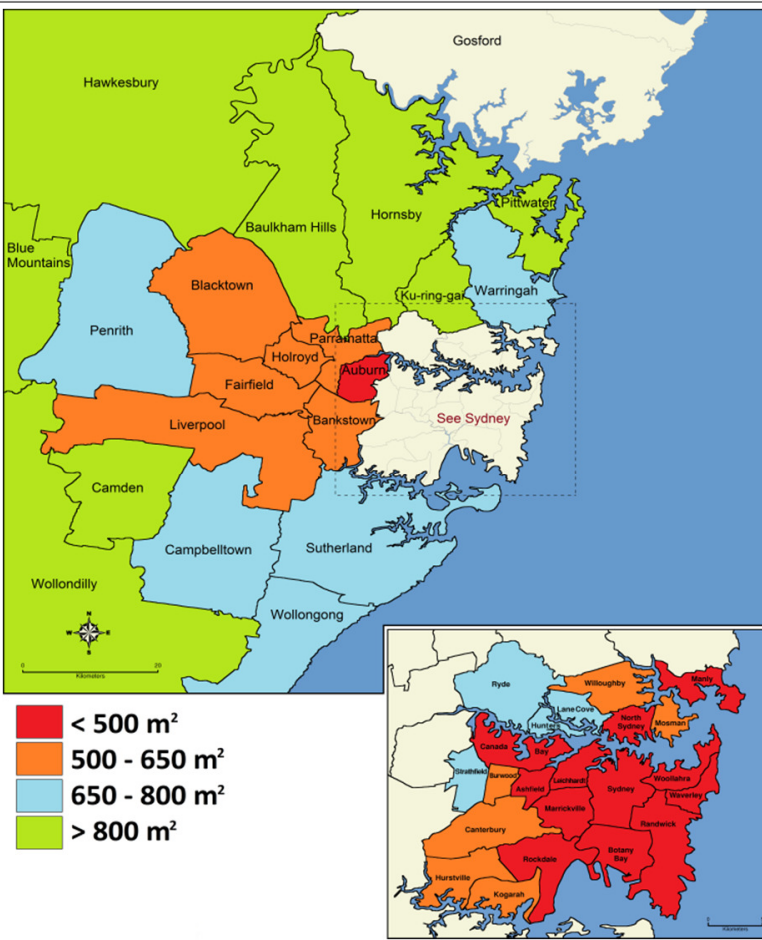

(a) Average lot sizes

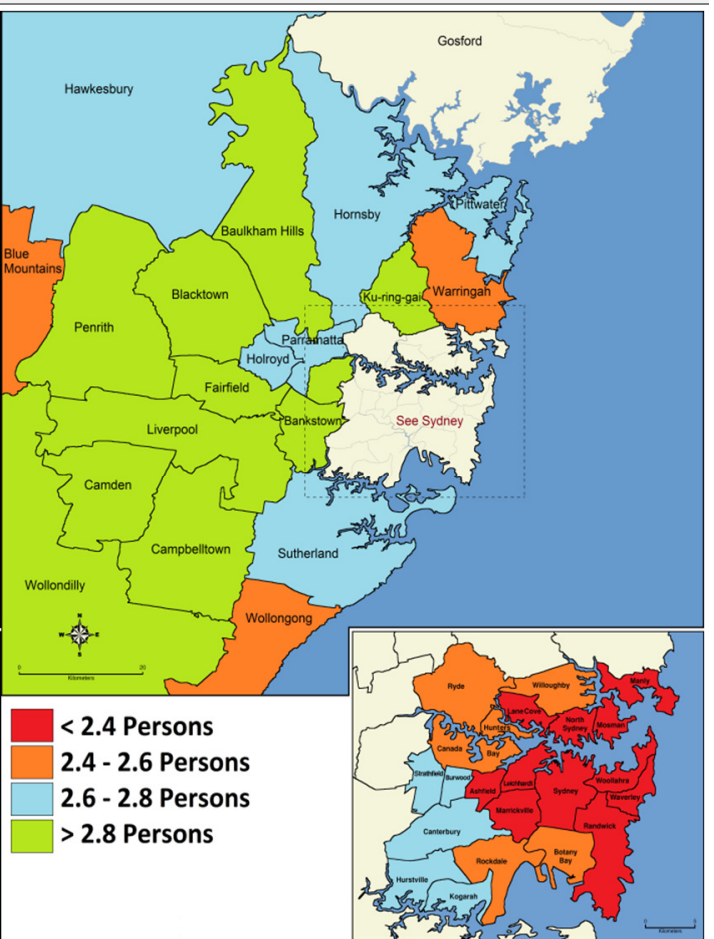

(b) Average number of persons per household

Figure 3. Average single dwelling property area and average number of persons per household in Sydney, data from Australian Bureau of Statistic [18, 19]

The SWC data shows an overall decline in the average annual water consumption per household in Sydney's metropolitan area during the study period (Q1-02 to Q4-09) from $282 \mathrm{~kL} /$ year in 2002 to $200 \mathrm{~kL} /$ year in 2009. Even without including the impact of rainwater tanks (discussed in the next section) the overall average water consumption fell by $24 \%$ over the study period. Table 1 summarises the reduction in water savings in all 44 LGAs. These reductions can be attributed to effective demand management techniques such as the Sydney-wide water restrictions between 2003 and 2009 [20] and the introduction of water efficient fixtures like taps, dual flush toilets and efficient shower heads. SWC installed these free of charge or at subsidised prices. Other factors included the implementation of BASIX for new and refurbished buildings, and the installation of new water efficient appliances. It may also be due to lot sizes becoming smaller in part due to sub-division of existing residential lots which leads to smaller gardens [21].

When comparing the reduction in the level of water consumption between the various LGAs (Figure 2a) it is evident that water reductions are smaller for properties with smaller lot areas (Figure 3a). The majority of LGAs in inner Sydney which have small lot areas had about $20 \%$ to less than $20 \%$ reductions in water usage. Most of the LGAs in the outer Sydney area with some exceptions (Liverpool, Fairfield, Holroyd, Parramatta, Auburn and Blacktown), had significant reductions, most of which were greater than $28 \%$.

A relationship exists between the water consumption in terms of per capita daily demand (L/person/day) compared to the number of people per household [22, 23]. Figure $3 \mathrm{~b}$ shows that as the number of people per household increases, water consumption (in per capita terms) (Figure $2 \mathrm{~b})$ generally decreases $\left(p=1.7 \mathrm{E}^{-41}<0.05\right)$. This is true for most LGAs in the inner Sydney area (except Leichardt and Marrickville) which have less people per household and higher per capita usage compared to most LGAs in the outer Sydney area (except Pittwater, Baulkham Hills, Hawkesbury, Wollongong and 
Sutherland). These areas have more people per household and lower per capita usage. The trend between water consumption is not completely explained by the house lot area and number of people per household. Socio-economic factors may be considered and they are explored in more detail below to assess their impact on water consumption.

Table 1. Percentage of water saved (standardised and non-standardised methods) by installing a Rainwater Tank (RWT) for LGAs in Sydney's Metropolitan Area

\begin{tabular}{|c|c|c|c|c|}
\hline LGA & $\begin{array}{c}\text { Annual water use } \\
\text { +/- Std. dev. } \\
{[\mathrm{kL} / \mathrm{hh}]^{1}}\end{array}$ & $\begin{array}{c}\text { Reduction in } \\
\text { water }^{+} \\
{[\%][\mathrm{kL} / \mathrm{hh}]^{1}}\end{array}$ & $\begin{array}{c}\text { Additional reduction } \\
\text { with RWT }[\%][\mathrm{kL} / \mathrm{hh}]^{1}\end{array}$ & $\begin{array}{c}\text { RWT } \\
\text { installed [\%] }\end{array}$ \\
\hline Ashfield & $233 \pm 24$ & $22(51)$ & $12(70)$ & 3.7 \\
\hline Auburn & $246 \pm 19$ & $11(27)$ & $11(70)$ & 1.9 \\
\hline Bankstown & $237 \pm 22$ & $19(45)$ & $10(70)$ & 2.8 \\
\hline Blacktown & $233 \pm 28$ & $24(56)$ & $10(70)$ & 2.8 \\
\hline Blue Mountains & $181 \pm 31$ & $32(58)$ & $9(70)$ & 12.2 \\
\hline Botany Bay & $254 \pm 24$ & $22(56)$ & $6(70)$ & 15.2 \\
\hline Burwood & $250 \pm 22$ & $19(48)$ & $8(70)$ & 2.1 \\
\hline Camden & $248 \pm 40$ & $29(72)$ & $7(70)$ & 6.8 \\
\hline Campbelltown & $242 \pm 34$ & $29(70)$ & $9(22)$ & 3.6 \\
\hline Canada Bay & $225 \pm 22$ & $19(43)$ & $11(25)$ & 3.6 \\
\hline Canterbury & $243 \pm 21$ & $19(46)$ & $10(24)$ & 2.3 \\
\hline Fairfield & $253 \pm 24$ & $19(48)$ & $9(23)$ & 3.1 \\
\hline Hawkesbury & $251 \pm 47$ & $32(80)$ & $8(20)$ & 7.0 \\
\hline Holroyd & $226 \pm 19$ & $17(38)$ & $9(20)$ & 4.1 \\
\hline Hornsby & $237 \pm 39$ & $30(71)$ & $11(26)$ & 7.0 \\
\hline Hunters Hill & $284 \pm 47$ & $31(88)$ & $12(34)$ & 7.9 \\
\hline Hurstville & $230 \pm 24$ & $21(48)$ & $12(28)$ & 4.0 \\
\hline Kiama & $172 \pm 21$ & $25(43)$ & $10(17)$ & 15.7 \\
\hline Kogarah & $244 \pm 27$ & $22(54)$ & $10(24)$ & 4.2 \\
\hline Ku-ring gai & $284 \pm 53$ & $34(97)$ & $11(31)$ & 7.5 \\
\hline Lane Cove & $249 \pm 37$ & $30(75)$ & $12(30)$ & 5.6 \\
\hline Leichhardt & $175 \pm 17$ & $20(35)$ & $9(16)$ & 2.0 \\
\hline Liverpool & $249 \pm 25$ & $19(47)$ & $7(17)$ & 2.8 \\
\hline Marrickville & $196 \pm 19$ & $22(43)$ & $11(22)$ & 1.8 \\
\hline Mosman & $284 \pm 38$ & $26(74)$ & $16(35)$ & 5.3 \\
\hline North Sydney & $215 \pm 27$ & $24(52)$ & $12(26)$ & 3.2 \\
\hline Parramatta & $230 \pm 25$ & $19(44)$ & $11(25)$ & 3.6 \\
\hline Penrith & $244 \pm 37$ & $29(71)$ & $7(17)$ & 5.2 \\
\hline Pittwater & $237 \pm 36$ & $30(71)$ & $12(28)$ & 7.5 \\
\hline Randwick & $242 \pm 26$ & $24(58)$ & $10(24)$ & 3.5 \\
\hline Rockdale & $242 \pm 22$ & $24(58)$ & $10(24)$ & 2.0 \\
\hline Ryde & $229 \pm 25$ & $22(50)$ & $11(25)$ & 4.2 \\
\hline Shellharbour & $206 \pm 22$ & $24(49)$ & 7 (14) & 17.0 \\
\hline Strathfield & $279 \pm 35$ & $21(59)$ & $7(20)$ & 3.0 \\
\hline Sutherland & $242 \pm 16$ & $29(70)$ & $9(22)$ & 7.4 \\
\hline Sydney CDB & $184 \pm 101$ & $20(37)$ & $9(17)$ & 0.7 \\
\hline Hills Shire & $276 \pm 46$ & $27(75)$ & $12(33)$ & 5.2 \\
\hline Warringah & $237 \pm 30$ & $24(57)$ & $11(26)$ & 5.5 \\
\hline Waverly & $232 \pm 20$ & $18(42)$ & $8(19)$ & 2.3 \\
\hline Willoughby & $239 \pm 30$ & $26(62)$ & $8(19)$ & 5.9 \\
\hline Wollondilly & $233 \pm 40$ & $29(68)$ & $9(21)$ & 12.0 \\
\hline Wollongong & $196 \pm 22$ & $25(49)$ & $8(16)$ & 16.4 \\
\hline Woollahra & $280 \pm 35$ & $23(64)$ & $9(25)$ & 2.3 \\
\hline Average & $236 \pm 31$ & $24(57)$ & $9(21)$ & 5.5 \\
\hline
\end{tabular}

${ }^{*}$ Average over the period 2002-2009, +/- Standard deviation, ${ }^{+}$Reduction in water consumption, ${ }^{1}[\mathrm{~kL} /$ household] 


\section{Socio-economic aspects}

Figure 4 (a-d) shows the distribution of socio-economic aspects such as levels of educational qualifications, mean taxable incomes, portion of rental properties and portion of residents born in Non-English-Speaking Countries (NESC) [24].

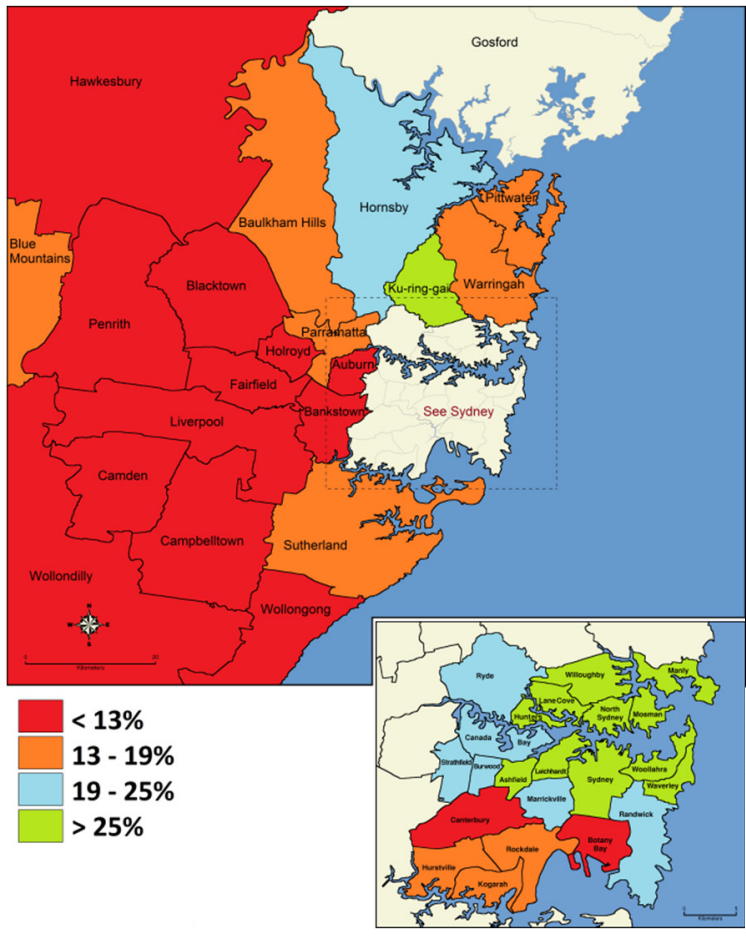

(a) Average number of people with Bachelor qualifications or higher

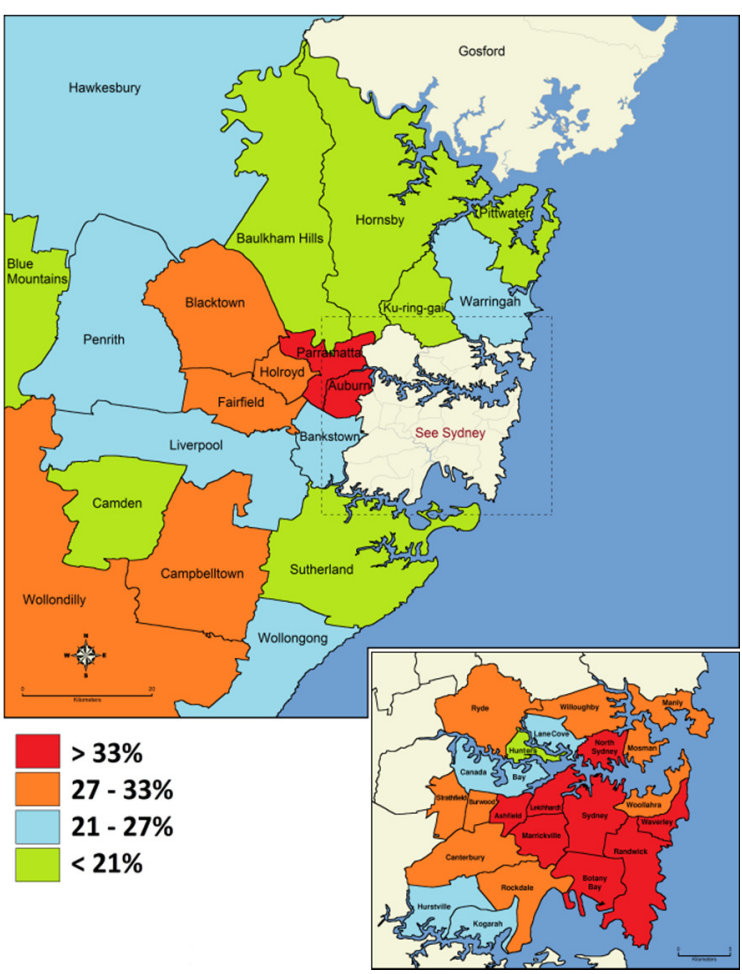

(c) Percentage of houses that are not owner occupied (rented)

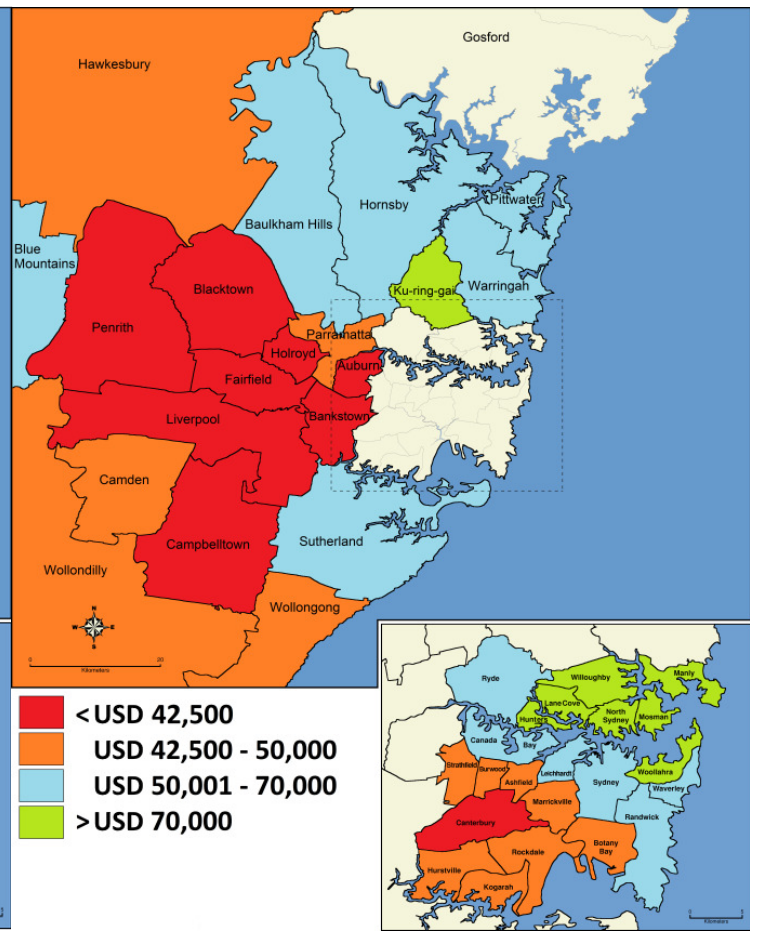

(b) Mean taxable income

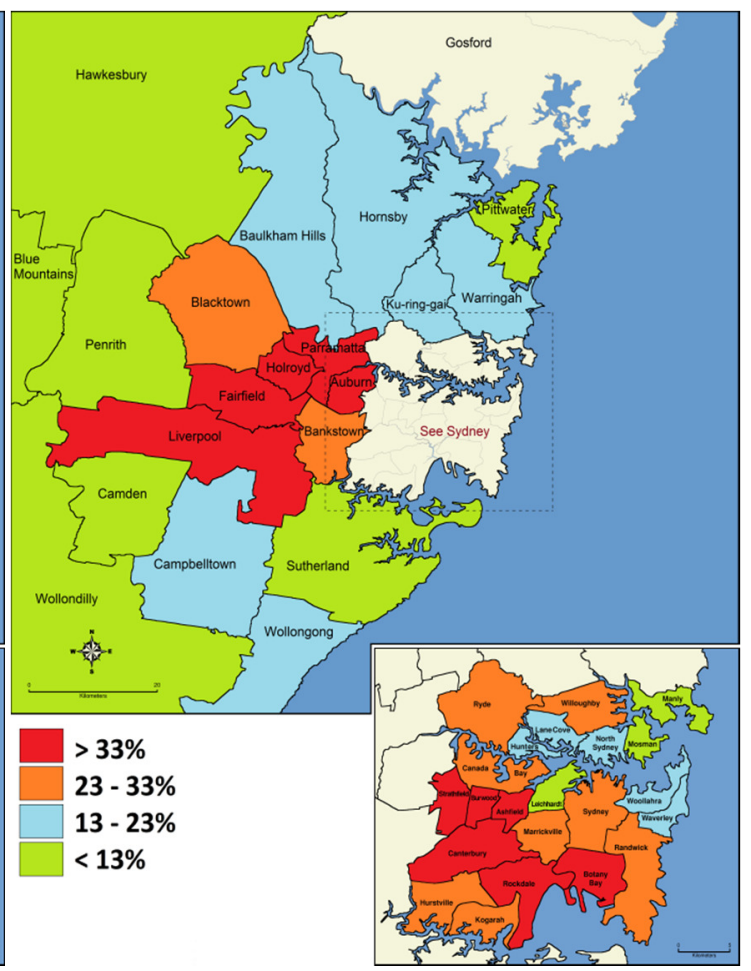

(d) Percentage of residents born in non-English speaking countries

Figure 4. Socio economic indicators in the Sydney metropolitan area, data from Australian Bureau of Statistic [18-19] 
Educational qualification and mean taxable income. Troy et al. [21] suggested that people with higher education qualifications and higher incomes generally consume more resources including water. Figure $4 \mathrm{a}$ shows that the education qualifications of people are much higher in the inner Sydney LGAs [24]. More than 1 in 4 people who live in harbour-side LGAs (Sydney, Woollahra, Waverley, Leichhardt, Ashfield, Hunters Hill, Lane Cove, North Sydney, Mosman, Willoughby and Manly) have a Bachelor degree or higher. This ratio is less than 1 in 7 in most of the LGAs west of the inner Sydney area. A larger proportion of people with higher educational qualifications in an LGA (Figure 4a) also correspond to higher than average individual taxable income (Figure 4b) [18]. Further, it appears most of the LGAs with higher levels of educational qualifications (Figure 4a) generally had households with fewer occupants (Figure 3b) $\left(p=3.7 \mathrm{E}^{-22}<0.05\right)$. These suburbs had a higher per-capita water consumption pattern (Figure 2b) $\left(p=4.4 \mathrm{E}^{-22}<0.05\right)$. This is true for most LGAs in the Sydney metropolitan area except for Sutherland, Baulkham Hills and Blue Mountains where there are less people with higher educational qualifications but they still have a fairly high individual taxable income. On the other hand, Ashfield which has more than 1 in 4 people with a Bachelor degree or higher, has an average individual taxable income similar to those LGAs with people who had low education qualifications, possibly due to a high number of students and recent migrants.

LGAs that are an exception to this trend are Leichhardt and Marrickville. Based on election returns, these two LGAs contain a higher number of supporters of environmentally aligned political parties compared to other LGAs. They also have large numbers of people with Bachelor degrees or higher qualifications. Leichhardt also has reasonably high income levels in-line with nearby suburbs (CBD Sydney, Randwick and Waverley). However, these LGAs have low water consumption levels in terms of daily household consumption and daily per-capita household consumption.

Rented properties. Figure 4c shows that in most inner Sydney LGAs more than 1 in 3 properties were rented while in the remaining inner Sydney LGAs the ratio was at least 1 in 4 properties. This is very different to most outer Sydney LGAs where less than 1 in 4 properties were rented. There seems to be no relationship between per-capita daily household water consumption to the proportion of rental properties in an LGA (Figure $2 \mathrm{~b}$ and $4 \mathrm{c})\left(p=7.4 \mathrm{E}^{-38}<0.05\right)$. Although some inner Sydney LGAs with more rental properties have higher per-capita water consumption levels (Figure $2 b$ and $4 c$ ), others with a high per-capita water consumption level have fewer rental properties.

People born in Non-English-Speaking Countries (NESC). There appears to be a relationship between the level of water consumption and the various LGAs (Figure 2b) where many people born in NESC live (Figure 4d). LGAs comprising a higher proportion of people born in NESC were LGAs south of Sydney (Botany Bay and Rockdale) and LGAs west of Sydney (Canterbury, Ashfield, Burwood, Strathfield, Auburn, Parramatta, Holroyd, Fairfield and Liverpool) (Figure 4d) [18]. These areas are generally the same areas which have less people with at least a Bachelor degree and lower than average individual taxable income (Figure 4a and 4b). With the exception of Strathfield and Ashfield, these areas generally have average or below average levels of per-capita water consumption (Figure 2b). Figure 2c shows that Strathfield had a very high level of household consumption whereas Ashfield was slightly below average. The remaining LGAs, with higher numbers of people born in NESC, generally had average levels of household consumption.

The LGAs with a higher proportion of people born in NESC generally had reduced levels of water consumption between 2001 and 2009, (Figure 2a). Other LGAs such as Campbelltown, Camden, Penrith and Hornsby, which have much less people born in 
NESC, had similar low average per-capita water consumption levels (Figure $2 b$ ) yet all had the biggest reductions in water consumption between 2001 and 2009 of more than $28 \%$ (Figure $2 \mathrm{a})\left(p=1.28 \mathrm{E}^{-04}<0.05\right)$. This could be due to the communication/ education barriers faced by people born in NESC who did not fully benefit from the education programs in water restriction regulations and water saving incentives that were run when these programs were implemented.

\section{Rainwater tanks}

Table 1 also provides the percentage of water savings by installing rainwater tanks. The average distribution of reduction in water savings across all 44 LGAs is $9 \% \pm 1.9 \%$. The statistical significance in the reduction of the mean water usage is extremely small $\left(p=1.9 \mathrm{E}^{-143}<0.05\right)$ due to the very large data set of properties on the SWC database. On average a household could save around $24 \mathrm{~kL}$ of water annually by installing a rainwater tank. This level of savings was compared to the findings of other studies undertaken on individual LGAs in Sydney's metropolitan area and surrounding LGAs that received SWC water. Moy [8] revealed households that installed rainwater tanks in Wollongong and Shellharbour reduced their water consumption by approximately $10.3 \%$ although this data was not adjusted for the overall reduction of water consumption that occurred in the wider community. Furthermore the reduction in water consumption was not individually reported for Wollongong LGA and Shellharbour LGA. Table 1 shows the reduction in water consumption due to rainwater tanks for Wollongong and Shellharbour was 7\% and $8 \%$, respectively in this study.

Knights et al. [9] presented data from the rainwater tank incentive scheme in Marrickville LGA indicating that rainwater tanks could reduce residential water consumption on average by $25 \%$. Again this data was not adjusted for the overall reduction of water consumption that occurred in the wider community. A comparison of the methods of analysis between the studies is difficult without knowing the full extent of the data sets selected and whether specific conditions were placed on removing any data (e.g. as was carried out in this study, and outlined in the 'SWC Database' section of this paper).

Figure 5a shows the level of uptake of the rainwater tank rebate in LGAs, and demonstrates that the largest adopters were Wollongong, Wollondilly and the Blue Mountains in the outer Sydney area, and Botany Bay in the inner Sydney area, with more than $10 \%$ of houses having received a rainwater tank rebate. Other outer Sydney LGAs with high levels (5 to 10\%) were Sutherland, Camden and Penrith, along with all northern LGAs from the Hawkesbury through to Pittwater and the inner Sydney LGAs of Hunters Hill, Lane Cove, Willoughby and Mosman. The remaining inner Sydney areas were evenly split between lower uptakes of 3 to $5 \%$ or less than $3 \%$. This could be due to the general lack of space for a rainwater tank in residential backyards in the inner Sydney locations (Figure 3a). Also a higher proportion of the houses were rented compared to the outer Sydney LGAs (Figure 4c). LGAs located in the outer Sydney area with more people born in NESC had lower levels of rainwater rebate uptake (between 3 to $5 \%$ or less than $3 \%$ ).

Figure $5 \mathrm{~b}$ shows the level of reduction in water consumption attributable only to installed rainwater tanks. The reduction in water consumption was calculated for rainwater tanks over a period of at least two years before and at least two years after their installation. The results indicate that most properties within inner Sydney with a rainwater tank achieved at least a 9 to $11 \%$ additional reduction in water usage, with more than half of those LGAs achieving more than $11 \%$ additional reductions. These same levels of water usage reductions were also observed for most of the northern and central LGAs in the outer Sydney area. 


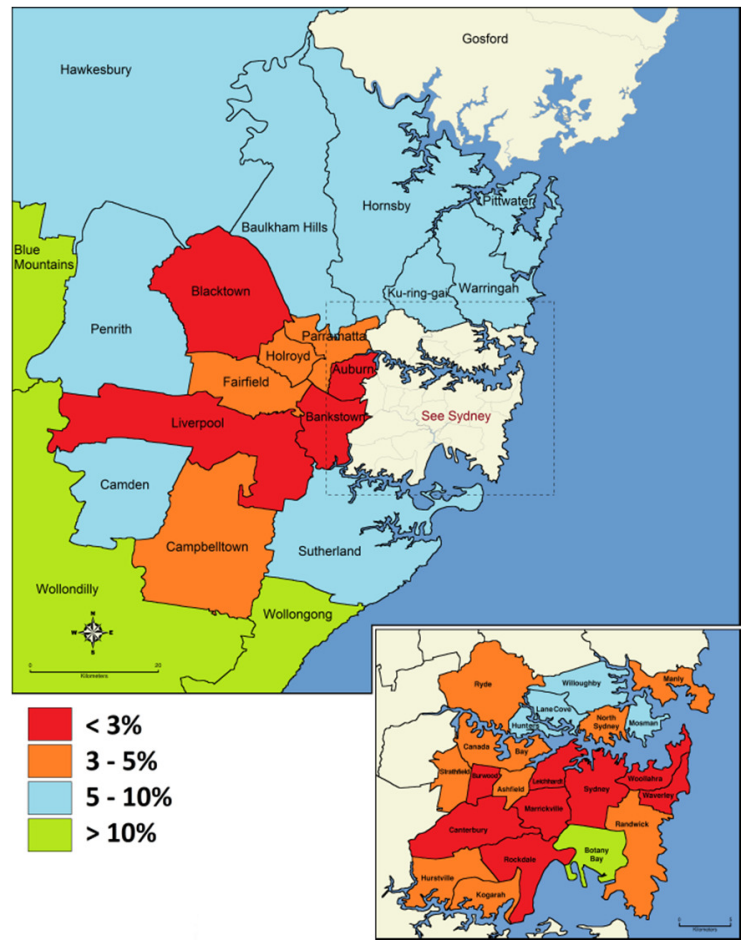

(a) Percentage of rebated rainwater tanks installed

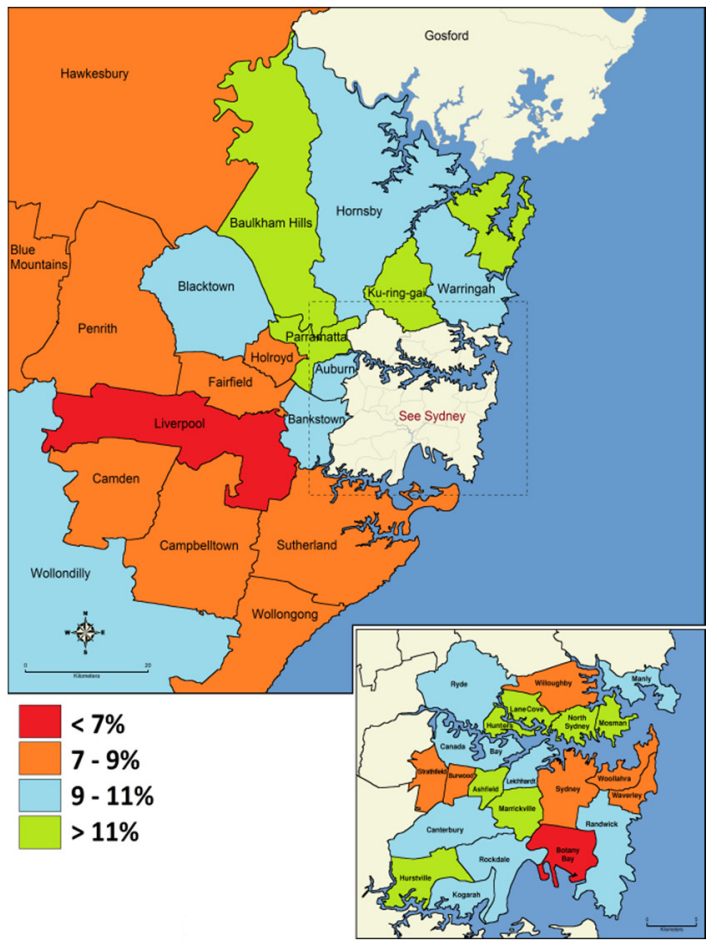

(b) Average percentage of water savings from rebated rainwater tanks

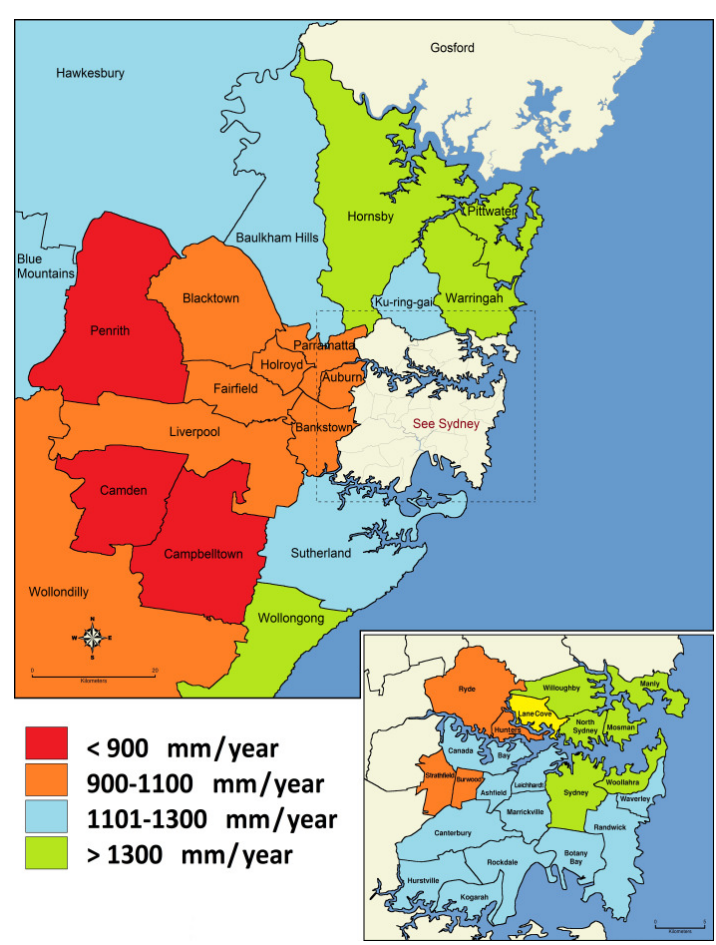

(c) Sydney Metropolitan area long term average rainfall by LGA from 1961 to 1990, data from Bureau of Meteorology [15, 25]

Figure 5. Average percentages of water savings from rebated rainwater tanks in the Sydney

A reason for this large reduction in water consumption in the inner Sydney LGAs as compared to southern and western outer Sydney LGAs (Figure 5b), could be explained by the smaller lot areas (Figure 3a) in the former. It is estimated that the sizes of the rainwater tanks would not differ all too much in inner and outer Sydney LGAs, as compared to the difference in lot sizes. In inner Sydney LGAs, there would be a higher 
yield of collected rainwater relative to the area of garden. A rainwater tank in the inner Sydney LGAs would likely contain enough yield for most if not all outdoor watering requirements, and perhaps completely replace the potable water needed for outdoor/garden use. In outer Sydney LGAs, with much larger outdoor and/or garden areas, rainwater can only supplement potable water supplies rather than replace it.

People born in NESC. Those central LGAs with more people born in NESC also experienced less water consumption reductions from 2002 to 2009. Generally they had a lower uptake of the rainwater rebate but nonetheless actually achieved high water usage reduction following the installation of rainwater tanks $\left(p=2.53 \mathrm{E}^{-15}<0.05\right)$. This could be due to the fact that the few people who received the grant in these LGAs were strongly motivated and recognised the great potential in saving water for gardening and other outdoor requirements.

Lot size. An analysis of the average lot size of properties that received rainwater tank rebates shows a bias to large properties $\left(p=4.3 \mathrm{E}^{-26}<0.05\right)$. This is likely due to people with larger properties having larger gardens and being able to better utilise and warrant a rainwater tank.

Influence of rainfall. The typical rainfall patterns show that the coastal and elevated areas of the Sydney Basin (Blue Mountains, Hawkesbury and Baulkham Hills) generally have higher levels of rainfall compared to other LGAs located away from the coastline. There appears to be some relationship between the average total annual rainfall (Figure 5c) for each LGA compared to the level of water usage reductions from installing a rainwater tank (Figure 5b). A few of the LGAs (Sydney, Marrickville, North Sydney, Mosman, Baulkham Hills and Hornsby) that had high levels of rainfall experienced higher levels of water usage reductions. Western and south-western LGAs in outer Sydney (from Parramatta to Penrith down to Wollondilly) that received less rainfall achieved lower water usage reduction levels. While this is true for some LGAs, there are also a significant number of LGAs (Botany Bay, Waverley, Woollahra, Leichhardt, Lane Cove, and Willoughby) that received high levels of rainfall but did not achieve large reductions in water usage and vice versa (Ryde, Strathfield and Burwood).

\section{CONCLUSIONS}

The analysis of the SWC data shows an overall decline in the average annual water consumption per household in Sydney metropolitan areas during the study period (2002-2009) from $282 \mathrm{~kL} /$ year to $200 \mathrm{~kL} / \mathrm{year}$. Even without including the impact of rainwater tanks the average water consumption decreased by $24 \%$ over the study period. In many LGAs in Sydney the reduction in water consumption was over $28 \%$ and up to $33.5 \%$. These reductions were due to the effective "demand management" techniques such as the Sydney-wide water restrictions and the introduction of water efficient fixtures like taps, dual flush toilets and efficient shower heads. The average percentage of water savings by installing rainwater tanks across all 44 LGAs was a further reduction of $9 \%$. In some LGAs the decline in water consumption due to rainwater tanks was up to $15 \%$. On average, a household could be expected to save around $24 \mathrm{~kL}$ of water annually by installing a rainwater tank controlling for the effects of other factors that influenced water usage.

The results were compared against socio-demographic factors using variables such as household size, educational qualifications, taxable income, rented properties, and non-English-speaking background, etc., to gain an appreciation of how these factors may have influenced the outcomes evident in the data. Among the co-relations found were 
that most properties within inner Sydney with a rainwater tank achieved at least a 9-11\% additional reduction in water usage, with more than half of those LGAs achieving more than $11 \%$; properties with larger land area were more likely to have a rainwater tank installed; LGAs with more people born in NESC had lower reduction in water consumption reductions.

\section{ACKNOWLEDGEMENT}

The study was funded by ARC LP (LP0776705) and Kogarah Council. Sydney Water Corporation provided the data for this study.

\section{REFERENCES}

1. Chanan, A. P., Vigneswaran, S., Kandasamy, J. K. and Simmons, B., Lessons for a Viable Water Recycling Industry, Proceedings of Institution of Civil Engineers, Water Manag., Vol. 164, No. 5, pp 213-219, 2011.

2. Kuczera, G., Urban Water Supply Drought Security: A Comparative Analysis of Complimentary Centralised and Decentralised Storage Systems (Lambert, M., Daniell, T. M. and Leonard, M., eds.), Proceedings of Water Down Under 2008, Engineers Australia, Modbury, South Australia, ISBN: 0858257351, 2008.

3. Coombes, P. and Barry, M., Determination of Available Storage in Rainwater Tanks Prior to Storm Events (Lambert, M., Daniell, T. M. and Leonard, M., eds.), Proceedings of Water Down Under 2008, Engineers Australia, Modbury, South Australia, ISBN: 0858257351, 2008.

4. Coombes, P. J. and Kuczera, G., Analysis of the Performance of Rainwater Tanks in Australian Capital Cities, 28 ${ }^{\text {th }}$ International Hydrology and Water Resources Symposium, The Engineers Australia, Wollongong, Australia, 10-11 November 2003.

5. Chong, M., Umapathi, S., Mankad, A., Gardner, T., Sharma, A. and Biermann, S., Estimating Water Savings from Mandated Rainwater Tanks in South East Queensland, $3^{\text {rd }}$ Urban Water Security Research Alliance Science Forum, pp 31-41, Brisbane, Australia, 14-15 September 2011.

6. Beal, C. D., Sharma, A., Gardner, T. and Chong, M., A Desktop Analysis of potable Water savings from Internally Plumbed Rainwater Tanks in South-East Queensland, Australia, Water Resour. Manag., Vol. 26, pp 1577-1590, 2012, https://doi.org/10.1007/s11269-011-9973-0

7. Ferguson, M., Rainwater Tank Monitoring Report: A 12-month One-minute Interval Data Study of Rainwater Tank Water Savings and Energy use for 52 Real Life Installations, Sydney Water Corporation, 2011.

8. Moy, C., Rainwater Tank Households: Water Savers or Water Users? Geograph. Res., Vol. 50, No. 2, 204-16, 2012, https://doi.org/10.1111/j.1745-5871.2011.00720.x

9. Knights, D., Hanley, C. and McAuley, A., Can Rainwater Tanks meet Multiple Sustainability Objectives? An Assessment of Water Conservation, Pollution Reduction and Frequent Flows from Rainwater Tanks in Sydney's Marrickville LGA, WSUD 2012: Water Sensitive Urban Design; Building the Water Sensitve Community, $7^{\text {th }}$ International Conference on Water Sensitive Urban Design, pp 179-185, Engineers Australia; Melbourne, Australia, 21-23 February 2012.

10. NSW, Water Smart Household, Water for Life Fact Sheet Series, A Water Plan from the NSW Government, NSW Government, Sydney, Australia, 2012.

11. ABS, Environmental Issues: Water use and Conservation, Statistic 4602.0.55.003, Australian Bureau of Statistics, Australian Government, Canberra, Australia, 2010.

12. Mehrabadi, M. H. R., Saghafian, B. and Fashi, F. H., Assessment of Residential Rainwater Harvesting Efficiency for Meeting Non-potable Water demands in Three Climate Conditions, Resources Conservation and Recycling, Vol. 73, pp 86-93, 2013, https://doi.org/10.1016/j.resconrec.2013.01.015 
13. Stratigea, D. and Makropoulos, C., Balancing Water demand reduction and Rainfall Runoff minimisation: Modelling Green Roofs, Rainwater Harvesting and Greywater Reuse Systems, Water Sci. Tech.: Water Supply, Vol. 15, No. 2, pp 248-255, 2014 , https://doi.org/10.2166/ws.2014.105

14. Van der Sterren, M., Rahman, A. and Dennis, G. R., Implications to Stormwater Management as a Result of Lot Scale Rainwater Tank Systems: A Case Study in Western Sydney, Australia, Water Sci. Tech., Vol. 65, No. 8, pp 1475-1482, 2012, https://doi.org/10.2166/wst.2012.033

15. BOM, Climate Data Online, Bureau of Meteorology, Australian Government, http://www.bom.gov.au/climate/data/, [Accessed: 02-June-2016]

16. Randolph, B. and Troy, P., Understanding Water Consumption in Sydney, State of Australian Cities Conference (SOAC), pp 900-911, Adelaide, Australia, 2007.

17. SWC, History of Water Restrictions, Sydney Water Corporation, Sydney, Australia, 2012, http://www.sydneywater.com.au/water4life/waterwise/WhenWereWaterRest rictionsIntroduced.cfm, [Accessed: 02-June-2016]

18. ABS, Estimates of Personal Income for Small Areas, Statistic 6524.0.55.002, Time Series, Australian Bureau of Statistics, Australian Government, Canberra, Australia, 2009.

19. ABS, Census of Population and Housing, Australian Bureau of Statistics, Australian Government, Canberra, Australia, 2006.

20. SWC, Water Restriction Rules Applicable in Blue Mountains, Illawarra and Sydney, Sydney Water, 2013, http://www.sydneywater.com.au/SW/findnow/index.htm?fn_url $=\mathrm{http}: / /$ Sydneywater.cust help.com/app/answers/detail/a_id/397, [Accessed: 02-June-2016]

21. Troy, P., Holloway, D. and Randolph, B., Water use and the Built Environment: Patterns of Water Consumption in Sydney, City Futures Research Report No. 1, City Futures Research Centre, Faculty of Built Environment, University of New South Wales, Sydney, Australia, 2005.

22. ABS, State of the Environment Reports, Water Services Association Australia (WSAA), Australian Bureau of Statistics, Canberra, Australia, 2005.

23. SWC, Water Wrap, Spring 2012, Sydney Water Corporation, Sydney, Australia, 2012, http://www.sydneywater.com.au/Publications/FactSheets/WaterWrapSpring2012.pdf\# Page $=1$, [Accessed: 15-January-2012]

24. ABS, New South Wales Regional Statistics, Australian Bureau of Statistics, Australian Government, Canberra, Australia, 2007.

25. BOM, Maps of Average Conditions, Bureau of Meteorology, Australian Government, 2016, http://www.bom.gov.au/climate/averages/maps.shtml, [Accessed: 02-June-2016]

Paper submitted: 03.09.2016

Paper revised: 17.10 .2016

Paper accepted: 18.10 .2016 